Nuffield Department of Primary Care Health Sciences, University of Oxford, Oxford OX2 6GG, UK

2 West Hertfordshire Hospitals NHS Trust, Watford, UK

3 West Hertfordshire Respiratory Service - Central London Community Healthcare, London, UK

Correspondence to: T Greenhalgh trish.greenhalgh@phc.ox.ac.uk

Cite this as: BMJ2020;370:m3026 http://dx.doi.org/10.1136/bmj.m3026 Published: 11 August 2020

PRACTICE POINTER

\title{
Management of post-acute covid-19 in primary care
}

\author{
Trisha Greenhalgh, ${ }^{1}$ Matthew Knight, ${ }^{2}$ Christine A'Court, ${ }^{1}$ Maria Buxton, ${ }^{3}$ Laiba Husain ${ }^{1}$
}

\section{What you need to know}

- Management of covid-19 after the first three weeks is currently based on limited evidence

- Approximately $10 \%$ of people experience prolonged illness after covid-19

- Many such patients recover spontaneously (if slowly) with holistic support, rest, symptomatic treatment, and gradual increase in activity

- Home pulse oximetry can be helpful in monitoring breathlessness

- Indications for specialist assessment include clinical concern along with respiratory, cardiac, or neurological symptoms that are new, persistent, or progressive

Post-acute covid-19 ("long covid") seems to be a multisystem disease, sometimes occurring after a relatively mild acute illness. ${ }^{1}$ Clinical management requires a whole-patient perspective. ${ }^{2}$ This article, intended for primary care clinicians, relates to the patient who has a delayed recovery from an episode of covid-19 that was managed in the community or in a standard hospital ward. Broadly, such patients can be divided into those who may have serious sequelae (such as thromboembolic complications) and those with a non-specific clinical picture, often dominated by fatigue and breathlessness. The specialist rehabilitation needs of a third group, covid-19 patients whose acute illness required intensive care, have been covered elsewhere. ${ }^{3}$

\section{Defining post-acute covid-19}

In the absence of agreed definitions, for the purposes of this article we define post-acute covid-19 as extending beyond three weeks from the onset of first symptoms and chronic covid-19 as extending beyond 12 weeks. Since many people were not tested, and false negative tests are common, ${ }^{4}$ we suggest that a positive test for covid-19 is not a prerequisite for diagnosis.

\section{How common is it?}

Around $10 \%$ of patients who have tested positive for SARS-CoV-2 virus remain unwell beyond three weeks, and a smaller proportion for months (see box 1$).{ }^{7}$ This is based on the UK COVID Symptom Study, in which people enter their ongoing symptoms on a smartphone app. This percentage is lower than that cited in many published observational studies, ${ }^{89}$ whose denominator populations were those admitted to hospital or attending specialist clinics. A recent US study found that only $65 \%$ of people had returned to their previous level of health 14-21 days after a positive test. $^{10}$
Box 1: A patient's account

My wife, kids, and I all had symptoms of presumed covid-19 in early April 2020. They were soon fine, but I was more unwell and ended up in bed extremely fatigued, lethargic, and without appetite for four days.

The only person whose symptoms persisted was myself, and the fatigue which I had experienced was still lingering in the background. From this point onwards, it became difficult to engage fully in day to day activities with my normal energy levels. Exercise, of which I do a fair amount, was not at all possible.

I continued to feel like this for another three weeks, before finally feeling completely overwhelmed. This happened very quickly and without warning, resulting in me heading for bed immediately as I felt so bad. For the next 72 hours, I felt unwell in a way that was bordering on not coping. I was feverish, soaked with sweat to the point of having to regularly towel myself down, and with a persistent headache that had no relief in spite of increased doses of paracetamol or ibuprofen.

My chest was painfully tight, and my breathing was slightly erratic; I began to experience a shortness of breath in random waves that didn't leave me gasping for air but certainly made me uncomfortable and very worried. My glands were swollen to the point that it was physically challenging to swallow, and this was only possible with severe discomfort. I felt physically exhausted, mentally drained, and, for the first time in my life, began to consider asking for additional help.

It was at this point that I noticed I had also not had any sense of smell for the past week, and this has continued to be the case since.

Overall, I spent seven days feeling like I had been knocked sideways. I rarely get unwell, and if I do it's a fleeting fling with something that is usually seasonal and easily self medicated. This felt very different and was particularly challenging as there were points during my sickness that I was completely overwhelmed.

As far as recovery goes, it has now taken a full seven to eight weeks to start feeling close to my normal self again. In the aftermath of this, I have continued to experience the following: fatigued to the point of having to sleep in the day, inability to exercise, continued shortness of breath both motionless and when exerting, small waves of anxiety, considerable depression, continued loss of smell. These are all post-symptoms that I have had no experience or medical history with, and so it has been difficult to wrestle with the unexpectedness of them.

I'm back out doing moderate exercise now and glad to be through what has been a very difficult 12 week cycle from start to end.

- 40 year old man, who was previously fit

We also recommend recent articles by a social scientist ${ }^{5}$ and clinical academic ${ }^{6}$ with prolonged covid-19 symptoms. 


\section{Why are some people affected?}

It is not known why some people's recovery is prolonged. Persistent viraemia due to weak or absent antibody response, ${ }^{11}$ relapse or reinfection, ${ }^{12}$ inflammatory and other immune reactions, ${ }^{13} 14$ deconditioning, ${ }^{2}$ and mental factors such as post-traumatic stress ${ }^{1516}$ may all contribute. Long term respiratory, musculoskeletal, and neuropsychiatric sequelae have been described for other coronaviruses (SARS and MERS), ${ }^{17^{-22}}$ and these have pathophysiological parallels with post-acute covid-19. ${ }^{23}$

\section{What are the symptoms?}

Post-acute covid-19 symptoms vary widely. Even so-called mild covid-19 may be associated with long term symptoms, most commonly cough, low grade fever, and fatigue, all of which may relapse and remit. ${ }^{47}$ Other reported symptoms include shortness of breath, chest pain, headaches, neurocognitive difficulties, muscle pains and weakness, gastrointestinal upset, rashes, metabolic disruption (such as poor control of diabetes), thromboembolic conditions, and depression and other mental health conditions. ${ }^{424}$ Skin rashes can take many forms including vesicular, maculopapular, urticarial, or chilblain-like lesions on the extremities (so called covid toe). ${ }^{25}$ There seems to be no need to refer or investigate these if the patient is otherwise well.

\section{What tests are required?}

Blood tests should be ordered selectively and for specific clinical indications after a careful history and examination (see infographic); the patient may not need any. Anaemia should be excluded in the breathless patient. Lymphopenia is a feature of severe, acute covid-19. Elevated biomarkers may include $\mathrm{C}$ reactive protein (for example, acute infection), white cell count (infection or inflammatory response), natriuretic peptides (for example, heart failure), ferritin (inflammation and continuing prothrombotic state), troponin (acute coronary syndrome or myocarditis) and D-dimer (thromboembolic disease). Troponin and D-dimer tests may be falsely positive, but a negative result can reduce clinical uncertainty. Further research is likely to refine the indications for, and interpretation of, diagnostic and monitoring tests in follow-up of covid-19.

For patients who were not admitted to intensive care, British Thoracic Society guidance on follow-up of covid-19 patients who have had a significant respiratory illness proposes community follow-up with a chest $\mathrm{x}$ ray at 12 weeks and referral for new, persistent, or progressive symptoms. ${ }^{26}$ For those with evidence of lung damage (such as persistent abnormal chest $\mathrm{x}$ ray and oximeter readings), referral to a respiratory service is recommended; subsequent early referral to pulmonary rehabilitation probably aids recovery. 


\section{thebmi Visual summary}

Post-acute covid-19 appears to be a multi-system disease, sometimes occurring after a relatively mild acute illness. Clinical management requires a whole-patient perspective. This graphic summarises the assessment and initial management of patients with delayed recovery from an episode of covid-19 that was managed in the community or in a standard hospital ward.

An uncertain picture
$\begin{aligned} & \text { The long term course } \\ & \text { of covid-19 is unknown. } \\ & \text { This graphic presesents } \\ & \text { an approach based on } \\ & \text { evidence available at } \\ & \text { the time of publication. }\end{aligned}$
However, caution is advised, as patients
may present atypically, and new
treatments are likely to emerge

\begin{tabular}{l}
\multicolumn{1}{c|}{$\begin{array}{c}\text { Managing } \\
\text { comorbidities }\end{array}$} \\
Many patients have \\
comorbidities including diabetes, \\
hypertension, kidney disease or \\
ischaemic heart disease. These \\
need to be managed in \\
conjuntion with covid-19 \\
treatment. Refer to condition \\
specific guidance, available in \\
the associated article by \\
Greenhalgh and colleagues
\end{tabular}

\section{Safety netting and referral}

The patient should seek medical advice if concerned, for example: Worsening breathlessness $\mathrm{PaO}_{2}<96 \%$ Unexplained chest pain New confusion Focal weakness Specialist referral may be indicated, based on clinical findings, for example:

Respiratory if suspected pulmonary embolism, severe pneumonia Cardiology if suspected
myocardial infarction, pericarditis, myocarditis or new heart failure

C. Neurology if suspected neurovascular or acute neurological event

\section{"Long covid" in primary care}

Assessment and initial management of patients with continuing symptoms

\section{Supporting recovery from covid-19}

After excluding serious ongoing complications or comorbidities, and until the results of long term follow-up studies are available, patients should be managed pragmatically and symptomatically with an emphasis on holistic support while avoiding over-investigation. ${ }^{2}$ Fever, for example, may be treated symptomatically with paracetamol or non-steroidal anti-inflammatory drugs. Monitoring functional status in post-acute coivd-19 patients is not yet an exact science. A post-covid-19 functional status scale has been developed pragmatically but not 
formally validated ${ }^{27}$-a simplified version of this is reproduced in the supplementary material.

Referral to a specialist rehabilitation service does not seem to be needed for most patients, who can expect a gradual, if sometimes protracted, improvement in energy levels and breathlessness, aided by careful pacing, prioritisation, and modest goal setting. In our experience, most but not all patients who were not admitted to hospital recover well with four to six weeks of light aerobic exercise (such as walking or Pilates), gradually increasing in intensity as tolerated. Those returning to employment may need support to negotiate a phased return. Box 5 links to patient resources, including a comprehensive patient guide from Homerton University Hospital. ${ }^{28}$

\section{Respiratory symptoms and support}

\section{Cough}

The British Thoracic Society defines chronic cough as one that persists beyond eight weeks. ${ }^{26}$ Up to that time, and unless there are signs of super-infection or other complications such as painful pleural inflammation, cough seems to be best managed with simple breathing control exercises ${ }^{28}$ (see box 2) and medication where indicated (such as proton pump inhibitors if reflux is suspected).

\section{Box 2: Breathing techniques}

About $80 \%$ of the work of breathing is done by the diaphragm. After illness or general deconditioning, the breathing pattern may be altered, with reduced diaphragmatic movement and greater use of neck and shoulder accessory muscles. This results in shallow breathing, increasing fatigue and breathlessness, and higher energy expenditure. The "breathing control" technique is aimed at normalising breathing patterns and increasing the efficiency of the respiratory muscles (including the diaphragm) resulting in less energy expenditure, less airway irritation, reduced fatigue, and improvement in breathlessness.

The patient should sit in a supported position and breathe in and out slowly, preferably in through the nose and out through the mouth, while relaxing the chest and shoulders and allowing the tummy to rise. They should aim for an inspiration to expiration ratio of 1:2. This technique can be used frequently throughout the day, in 5-10 minute bursts (or longer if helpful).

Other breathing techniques-such as diaphragmatic breathing, slow deep breathing, pursed lip breathing, yoga techniques, Buteyko-are used in strategies to manage patients' breathing patterns and breathlessness but require specialist advice to identify which technique best suits each patient.

\section{Breathlessness}

A degree of breathlessness is common after acute covid-19. Severe breathlessness, which is rare in patients who were not hospitalised, may require urgent referral. Breathlessness tends to improve with breathing exercises (box 2). Pulse oximeters may be extremely useful for assessing and monitoring respiratory symptoms after covid-19, and we could find no evidence that their use in the home leads to increased anxiety (box 3).

\section{Box 3: Use of pulse oximetry in post-acute covid-19}

Hypoxia may reflect impaired oxygen diffusion and is a recognised feature of covid-19. It may be asymptomatic (so called silent hypoxia ${ }^{29}$ ) or symptomatic (reflecting increased work of breathing, or secondary pathology such as a bacterial pneumonia or thromboembolism). Oxygen saturation probes (pulse oximeters) have been used as part of a package of care for patients with covid-19 and are recommended as part of the assessment of acute covid-19 in national and local guidelines. $30-32$ Self monitoring of oxygen saturations over three to five days may be useful in the assessment and reassurance of patients with persistent dyspnoea in the post-acute phase, especially those in whom baseline saturations are normal and no other cause for dyspnoea is found on thorough evaluation. An exertional desaturation test should be performed as part of baseline assessment for patients whose resting pulse oximeter reading is $96 \%$ or above but whose symptoms suggest exertional desaturation (such as light-headedness or severe breathlessness on exercise). In the absence of contraindications, such patients should be invited to repeat the oximeter reading after 40 steps on a flat surface (if self testing remotely) and then after spending one minute doing

sit-to-stand as fast as they can (if supervised on site). ${ }^{33} \mathrm{~A}$ fall of $3 \%$ in the saturation reading on mild exertion is abnormal and requires investigation. 33

Patients should be provided with a pulse oximeter and an observations diary and given instructions for how to self monitor. 34 Typically, this would be a daily reading taken on a clean, warm finger without nail polish, after resting for 20 minutes; the device should be left to stabilise and the highest reading obtained should be recorded. While the range of commercially available oxygen saturation probes from healthcare suppliers and pharmacies seem to work within normal ranges ( $92 \%$ and above), smartphone apps that purport to measure oxygen saturations using the phone camera and torch should not be used. 35

British Thoracic Society guidelines define the target range for oxygen saturation as $94-98 \%$ and a level of $92 \%$ or below as requiring supplementary oxygen (unless the patient is in chronic respiratory failure). ${ }^{36}$ In the context of a normal assessment (history, examination, and appropriate investigations) without red flags, an oxygen saturation of $96 \%$ or above and the absence of desaturation on exertional tests is very reassuring. Further investigation or referral in the first six weeks after covid-19 in such patients is rarely indicated, though regular support by telephone or video is likely to be appreciated. Oximeter readings persistently in the $94-95 \%$ range or below (indicating substantially farther down the oxygen-haemoglobin desaturation curve ${ }^{37}$ ) require assessment and investigation. The patient should be provided with safety-netting advice (such as contacting their general practice or NHS111) in the event of recurrent low saturation readings. Appropriate adjustments should be made for patients with lung disease and known hypoxia-in whom the range of $88-92 \%$ is considered acceptable.

Recovery after any severe debilitating illness may be prolonged. ${ }^{38}$ Survivors of covid-19 acute respiratory distress syndrome are at risk of long term impairment of lung function. ${ }^{39-41}$ Serious interstitial lung disease seems to be rare in patients who are not hypoxic, though data on long term outcomes are not yet available. ${ }^{42}$

\section{Pulmonary rehabilitation}

Many patients are still recovering spontaneously in the first six weeks after acute covid-19 and do not generally require fast-track entry into a pulmonary rehabilitation programme. Those who have had significant respiratory illness may benefit from pulmonary rehabilitation, defined as "a multidisciplinary intervention based on personalised evaluation and treatment which includes, but is not limited to, exercise training, education, and behavioural modification designed to improve the physical and psychological condition of people with respiratory disease." 43 In the context of covid-19, rehabilitation is being delivered by various virtual models, including video linked classes and home education booklets with additional telephone support. We describe one such programme in the supplementary material on bmj.com.

\section{Fatigue}

The profound and prolonged nature of fatigue in some post-acute covid-19 patients shares features with chronic fatigue syndrome described after other serious infections including SARS, MERS, and community acquired pneumonia. 19202244 We found no published research evidence on the efficacy of either pharmacological or non-pharmacological interventions on fatigue after covid-19. Patient resources on fatigue management 45 and guidance for clinicians on 
return to exercise ${ }^{43}$ and graded return to performance for athletes (box 4) ${ }^{46}$ in covid-19 are currently all based on indirect evidence.

\section{Box 4: The sportsperson returning to exercise (summarised from} Stanford-Hall statement ${ }^{43}$ )

- After recovery from mild illness: 1 week of low level stretching and strengthening before targeted cardiovascular sessions

- Very mild symptoms: limit activity to slow walking or equivalent. Increase rest periods if symptoms worsen. Avoid high-intensity training

- Persistent symptoms (such as fatigue, cough, breathlessness, fever): limit activity to $60 \%$ maximum heart rate until 2-3 weeks after symptoms resolve

- Patients who had lymphopenia or required oxygen need respiratory assessment before resuming exercise

- Patients who had cardiac involvement need cardiac assessment before resuming

There is much debate and controversy about the role of graded exercise in chronic fatigue generally (see patient responses to a recent Cochrane review ${ }^{47}$ ) and in covid-19 in particular (see a recent statement from the National Institute for Health and Care Excellence $\left.(\mathrm{NICE})^{48}\right)$. Pending direct evidence from research studies, we suggest that exercise in such patients should be undertaken cautiously and cut back if the patient develops fever, breathlessness, severe fatigue, or muscle aches. Understanding, support, and reassurance from the primary care clinician are a crucial component of management.

\section{Cardiopulmonary complications, assessment and management}

Perhaps $20 \%$ of patients admitted with covid-19 have clinically significant cardiac involvement 4950 ; occult involvement may be even commoner. ${ }^{51}{ }^{52}$ Cardiopulmonary complications include myocarditis, pericarditis, myocardial infarction, dysrhythmias, and pulmonary embolus; they may present several weeks after acute covid-19. They are commoner in patients with pre-existing cardiovascular disease, ${ }^{49}$ but they have also been described in young, previously active patients. 435354 Various pathophysiological mechanisms have been proposed, including viral infiltration, inflammation and microthrombi, and down-regulation of ACE-2 receptors. 515354

\section{Chest pain}

Chest pain is common in post-acute covid-19. The clinical priority is to separate musculoskeletal and other non-specific chest pain (for example, the symptom described by a large patient-led survey as "lung burn"4) from serious cardiovascular conditions. Clinical assessment of the post-acute covid-19 patient with chest pain should follow similar principles to that for any chest pain: a careful history, taking account of past medical history and risk factors, a physical examination, backed up as indicated by investigations

(infographic). ${ }^{43}$ Where the diagnosis is uncertain, or the patient is acutely unwell, urgent cardiology referral may be needed for specialist assessment and investigations (including

echocardiography, computed tomography of the chest, or cardiac magnetic resonance imaging).

\section{Thromboembolism}

Covid-19 is an inflammatory and hypercoagulable state, ${ }^{50}$ with an increased risk of thromboembolic events. ${ }^{55}{ }^{56}$ Many hospitalised patients receive prophylactic anticoagulation. Recommendations for anticoagulation after discharge vary, but higher risk patients are typically discharged from hospital with 10 days of extended thromboprophylaxis. ${ }^{57}$ If the patient has been diagnosed with a thrombotic episode, anticoagulation and further investigation and monitoring should follow standard guidelines. ${ }^{58}$ It is not known how long patients remain hypercoagulable following acute covid-19.

\section{Ventricular dysfunction}

Left ventricular systolic dysfunction and heart failure after covid-19 can be managed according to standard guidelines. ${ }^{59}$ Intense cardiovascular exercise must be avoided for three months in all patients after myocarditis or pericarditis; athletes are advised to take three to six months of complete rest from cardiovascular training followed by specialist follow-up, with return to sport guided by functional status, biomarkers, absence of dysrhythmias, and evidence of normal left ventricular systolic function. ${ }^{60}$

\section{Neurological sequelae}

Ischaemic stroke, seizures, encephalitis, and cranial neuropathies have been described after covid-19, but these all seem to be rare. ${ }^{61}$ A patient suspected of these serious complications should be referred to a neurologist. Common non-specific neurological symptoms, which seem to co-occur with fatigue and breathlessness, include headaches, dizziness, and cognitive blunting ("brain fog"). 4 Until evidence based guidance appears on how to manage or when to refer such symptoms, we recommend supportive management and symptom monitoring in primary care.

\section{The older patient}

Covid-19 tends to affect older patients more severely. ${ }^{62}$ Those who survive are at high risk of sarcopenia, malnutrition, depression, and delirium. ${ }^{2}$ Post-covid-19 chronic pain may affect patients of any age but seems to be commoner in elderly patients. ${ }^{63}$ Physical symptoms add to the psychosocial impact of disrupted access to health care (such as arrangements for obtaining regular medication), core personal routines (such as walking to local shops), social interactions (such as meeting friends), and lay and professional support networks. ${ }^{64}$ Support should be personalised with input from the multi-professional team (for example, general practitioner, district nurse, social worker, rehabilitation teams, and occupational therapist as needed).

\section{Mental health and wellbeing}

Most publications on covid-19 and mental health have emphasised individual reactions to the pandemic such as anxiety, stress, and conditions related to broken routines, loneliness, and social isolation in uninfected individuals ${ }^{6566}$; the World Health Organisation has issued guidance on these. ${ }^{67}$ Lay accounts suggest that post-acute covid-19 is often associated with low mood, hopelessness, heightened anxiety, and difficulty sleeping. 6 Post-traumatic stress disorder may occur, especially in healthcare workers and others with caring responsibilities. ${ }^{15} 1643$

While a minority of patients may benefit from referral to mental health services, it is important not to pathologise the majority. Physical manifestations of covid-19 may distort responses to assessment tools (such as the PHQ9) designed to measure anxiety and depression in a physically healthy population, though these complications may occur. Patient organisations emphasise wellbeing, mindfulness, social connection, self care (including diet and hydration), peer support, and symptom control. Mental illness is strongly associated with social determinants such as poverty, discrimination, and social exclusion; mental health and wellbeing are enhanced by increased social solidarity, informal social support, mutual aid, and other community based and collective measures. ${ }^{68} 69$ Given how pervasive and unequal the impact of covid-19 has been, ${ }^{70} 71$ community level, cross-sector collaborations may be needed to develop locally relevant solutions. A recent report 
from general practice in a deprived area of Glasgow describes the importance of accessible, relationship-based care for patients with complex needs, and of system-level interventions such as attached financial advisers and outreach mental health services. ${ }^{69}$

\section{Social and cultural considerations}

Covid-19 is more common and has a worse prognosis in the acute phase in people who are poor, elderly, and from certain minority ethnic groups (notably black, south Asian, and Jewish ${ }^{70}$ ). It is too early to say whether these sociodemographic patterns persist in post-acute covid-19. Our own experience suggests that patients with post-acute covid-19 are from diverse social and cultural backgrounds. Many have comorbidities including diabetes, hypertension, kidney disease, or ischaemic heart disease. Some have experienced family bereavements as well as job losses and consequent financial stress and food poverty. Strain on many carers has been high. For an important few, lockdown has worsened safeguarding concerns such as the risk of child or intimate partner abuse. A detailed discussion of all these issues is beyond the scope of this article, but there are strong arguments for working with other agencies to develop local, system-level solutions. Box 5 provides some links to covid-19 advice from specialist social care, lay care, and faith organisations.

Box 5: Additional resources for patients and professionals

Advice for patients

- Homerton University Hospital. ACERS: Post COVID-19 patient information pack. https://www.hackneycitizen.co.uk/wp-content/uploads/Post-COVID-19-information-pack-5.pdf

- Royal College of Occupational Therapists. How to conserve your energy: Practical advice for people during and after having COVID-19. https://www.rcot.co.uk/conserving-energy

- Chartered Society of Physiotherapy. Covid-19: The road to recovery activity planner. https://www.csp.org.uk/system/files/documents/2020-06/001751_covid19-the_road_to_recovery_activity_planner_v3.pdf

- Mental Health Foundation. How to look after your mental health during the coronavirus outbreak. https://www.mentalhealth.org.uk/coronavirus

- Mind. Coronavirus and your mental health. https://www.mind.org.uk/information-support/coronavirus/

- Asthma UK and British Lung Foundation. Post-COVID HUB. https://www.post-covid.org.uk/

- Facebook. Long Covid Support Group. https://www.facebook.com/groups/longcovid

\section{Social, financial, and cultural support}

- Citizens Advice Bureau. Helping people through the COVID-19 pandemic. https://www.citizensadvice.org.uk/cymraeg/aboutus/policy/policy-research-topics/welfare-policy-research-surveys and-consultation-responses/welfare-policy-research/helping-peoplethrough-the-covid-19-pandemic/

- Advisory Conciliation and Arbitration Service (ACAS). Coronavirus (COVID-19): advice for employers and employees.

https://www.acas.org.uk/coronavirus

- Social Care Institute for Excellence. Supporting people who are isolated or at risk during the COVID-19 crisis.

https://www.scie.org.uk/care-providers/coronavirus-covid-19/support-for-isolated

- Carers UK. Coronavirus guidance. https://www.carersuk.org/helpand-advice/coronavirus-covid-19/coronavirus-covid-19

- Faith organisations:
- Sikh Helpline. Coronavirus update.

https://www.sikhhelpline.com/coronavirus/

- Jewish Care. Online and local resource library. https://www.jewishcare.org/informationduringcovid

- Muslim Council of Britain. COVID-19 guidance for Muslim communities. https://mcb.org.uk/resources/coronavirus/

- Ethnic organisations:

- Ubele. COVID-19 resource page for African diaspora communities. https://www.ubele.org/

- Greater Manchester Centre for Voluntary Organisation. Support and resources for BAME Communities. https://www.gmcvo.org.uk/Coronavirus/BAMESupport

\section{Professional guidelines and resources}

- European Respiratory Society. ERS COVID-19 resource centre. https://www.ersnet.org/the-society/news/novel-coronavirus-outbreak--update-and-information-for-healthcare-professionals

- European Cardiology Society. COVID-19 and cardiology. https://www.escardio.org/Education/COVID-19-and-CardiologyEuropean Cardiology Society

- Diabetes UK. Advice for healthcare professionals on coronavirus (Covid-19) and diabetes. https://www.diabetes.org.uk/professionals/resources/coronavirus-clinical-guidance

- Renal Association. COVID-19: Information and guidance for renal professionals. https://renal.org/covid-19/

- Royal College of Psychiatrists. COVID-19: Guidance for clinicians. https://www.rcpsych.ac.uk/about-us/responding-to-covid-19/responding-to-covid-19-guidance-for-clinicians

- British Geriatric Association:

- Coronavirus and older people. https://www.bgs.org.uk/resources/resource-series/coronavirus-and-older-people 2020

- COVID-19: Managing the COVID-19 pandemic in care homes for older people. https://www.bgs.org.uk/resources/covid-19-managing-the-covid-19-pandemic-in-care-homes

\section{Implications for the primary care team}

From the limited current evidence, we anticipate that many patients whose covid-19 illness is prolonged will recover without specialist input through a holistic and paced approach. Much can be achieved through interprofessional, community-facing rehabilitation services which embrace patient self management and peer support and harness the potential of video and other remote technologies. An information platform for the public has recently been launched, and a virtual rehabilitation platform is planned for later in 2020. ${ }^{72}$ Management of post-acute covid-19 must occur in conjunction with management of pre-existing or new comorbidities (see professional resources in box 5).

The natural history of post-acute and chronic covid-19 in a community population is unknown at the time of writing. The results of ongoing research studies 7374 are eagerly awaited. If $10 \%$ of covid-19 survivors experience post-acute disease, and we assume (conservatively) that half of all cases were not formally diagnosed, this translates to around 60 ooo people in UK with post-acute covid-19 (around six per general practice). Patients, many of whom were young and fit before their illness, have described being dismissed or treated as hypochondriacs by health professionals. ${ }^{4}$ They have rightly contested the classification of non-hospitalised covid-19 as "mild." In these uncertain times, one key role that the primary care practitioner can play is that of witness, "honouring 
the story" of the patient whose protracted recovery was unexpected, alarming, and does not make sense. ${ }^{75}$

\section{How this article was created}

There are not yet definitive, evidence based recommendations for the management of post-acute covid-19. We therefore used a pragmatic approach based on published studies on SARS and MERS, ${ }^{17-22}$ early editorials and consensus based guidance on covid-19, ${ }^{26} 4376-80 \mathrm{a}$ living systematic review, ${ }^{81}$ early reports of telerehabilitation (support and exercise via video link ${ }^{8182}$ ), and our own clinical experience. Academic sources were identified using a systematic search of PubMed database up to 10 July 2020 with the following terms: management of chronic covid-19, long-term sequelae, rehabilitation, mental health, chronic and post-acute care; we supplemented this by citation chaining key papers in Google Scholar.

\section{How patients were involved in the creation of this article}

A patient contributed to the description in box 1 . The paper was read by four additional lay people with experience of covid-19 in themselves or their friends or relatives, and extensively modified in response to their feedback before submission. Peer reviewers included people with post-acute covid-19. The main changes in response to patient feedback were in relation to management of fatigue.

Contributors: MK and TG jointly conceived the article and are guarantors. MK and MB provided a detailed service model and primary data on 1500 patients followed up in the Watford Virtual Ward service. Literature review was undertaken by TG and LH, supported by professional librarian Nia Roberts. TG wrote an initial draft of the paper and infographic, drawing on detail on rehabilitation provided by $\mathrm{MB}$ and cardiac complications by CA'C. All authors provided additional information and references and contributed to several iterations of the paper and infographic.

Competing interests: We have read and understood BMJ policy on declaration of interests and have no relevant interests to declare

Patient consent: Patient consent obtained

We thank Nia Roberts for specialist help with database searches and the patient (who wished to remain anonymous) for the descriptions in box 1. We thank Anica Alvarez Nishio, Jake Suett, Paul Garner and another anonymous patient reviewer who commented on earlier drafts. We also thank two editors and four reviewers, one with lived experience of post-acute covid-19, for extremely helpful feedback on a previous draft.

1 Geddes L. Why strange and debilitating coronavirus symptoms can last for months. New Scientist 2020. https://www.newscientist.com/article/mg24632881-400-why-strange-and-debilitatingcoronavirus-symptoms-can-last-for-months/.

2 Gemelli Against COVID-19 Post-Acute Care Study Group. Post-COVID-19 global health strategies: the need for an interdisciplinary approach. Aging Clin Exp Res 2020 doi: 10.1007/s40520-020-01616-x. pmid: 32529595

3 Phillips M, Turner-Stokes L, Wade D, et al. Rehabilitation in the wake of Covid-19-A phoenix from the ashes. British Society of Rehabilitation Medicine, 2020. https://www.bsrm.org.uk/downloads/covid-19bsrmissue1-published-27-4-2020.pdf.

4 Assaf G, Davis H, McCorkell L, et al. An analysis of the prolonged COVID-19 symptoms survey by Patient-Led Research Team. Patient Led Research, 2020. https://patientresearchcovid19.com/.

5 Callard F. Very, very mild: Covid-19 symptoms and illness classification. Somatosphere 2020; http://somatosphere.net/2020/mild-covid.html/.

6 Garner P. Covid-19 at 14 weeks - phantom speed cameras, unknown limits, and harsh penalties. BMJ Opinion [blog]. 2020; https://blogs.bmj.com/bmj/2020/06/23/paul-garner-covid-19-at-14 weeks-phantom-speed-cameras-unknown-limits-and-harsh-penalties/.

7 COVID Symptom Study. How long does COVID-19 last? Kings College London, 2020 https://covid19.joinzoe.com/post/covid-long-term?fbclid=IwAR1RxIcmmdL-EFjh_al-.

8 Sheehy LM. Considerations for postacute rehabilitation for survivors of COVID-19. JMIR Public Health Surveill 2020;6:. doi: 10.2196/19462 pmid: 32369030

9 Carfi A, Bernabei R, Landi FGemelli Against COVID-19 Post-Acute Care Study Group. Persistent symptoms in patients after acute COVID-19. JAMA 2020;

doi: 10.1001/jama.2020.12603 pmid: 32644129

10 Tenforde MW, Kim SS, Lindsell CJ, etallVY Network InvestigatorSCDC COVID-19 Response TeamIVY Network Investigators. Symptom duration and risk factors for delayed return to usual health among outpatients with COVID-19 in a multistate health care systems network - United States, March-June 2020. MMWR Morb Mortal Wkly Rep 2020;69:993-8.

https://www.cdc.gov/mmwr/volumes/69/wr/mm6930e1.htm.

doi: 10.15585/mmwr.mm6930e1 pmid: 32730238
11 Wu F, Wang A, Liu M, et al. Neutralizing antibody responses to SARS-CoV-2 in a COVID-19 recovered patient cohort and their implications. 2020. https://www.medrxiv.org/content/medrx iv/early/2020/04/06/2020.03.30.20047365.full.pdf

12 Lan L, Xu D, Ye G, etal. Positive RT-PCR test results in patients recovered from COVID-19. JAMA 2020;323:1502-3. doi: 10.1001/jama.2020.2783 pmid: 32105304

13 Colafrancesco S, Alessandri C, Conti F, Priori R. COVID-19 gone bad: A new character in the spectrum of the hyperferritinemic syndrome?Autoimmun Rev 2020;19:. doi: 10.1016/j.autrev.2020.102573 pmid: 32387470

14 Tay MZ, Poh CM, Rénia L, MacAry PA, Ng LFP. The trinity of COVID-19: immunity, inflammation and intervention. Nat Rev Immunol 2020;20:363-74 doi: 10.1038/s41577-020-0311-8 pmid: 32346093

15 Forte G, Favieri F, Tambelli R, Casagrande M. COVID-19 pandemic in the Italian population: validation of a post-traumatic stress disorder questionnaire and prevalence of PTSD symptomatology. Int J Environ Res Public Health 2020;17:4151. doi: 10.3390/ijerph17114151 pmid: 32532077

16 Jiang H-j, Nan J, Lv Z-y, etal. Psychological impacts of the COVID-19 epidemic on Chinese people: Exposure, post-traumatic stress symptom, and emotion regulation. Asian Pac J Trop Med 2020;13:252.

17 Ngai JC, Ko FW, Ng SS, To KW, Tong M, Hui DS. The long-term impact of severe acute respiratory syndrome on pulmonary function, exercise capacity and health status. Respirology 2010;15:543-50. doi: 10.1111/.1440-1843.2010.01720.x pmid: 20337995

18 Hosseiny M, Kooraki S, Gholamrezanezhad A, Reddy S, Myers L. Radiology perspective of coronavirus disease 2019 (COVID-19): lessons from severe acute respiratory syndrome and Middle East respiratory syndrome. A/R Am J Roentgenol 2020;214:1078-82. doi: 10.2214/AJR.20.22969 pmid: 32108495

19 Hui DS, Wong KT, Antonio GE, Tong M, Chan DP, Sung JJ. Long-term sequelae of SARS: physical, neuropsychiatric, and quality-of-life assessment. Hong Kong Med /2009;15(Suppl 8):21-3.pmid: 20393208

20 Lam MH-B, Wing Y-K, Yu MW-M, etal. Mental morbidities and chronic fatigue in severe acute respiratory syndrome survivors: long-term follow-up. Arch Intern Med 2009;169:2142-7. doi: 10.1001/archinternmed.2009.384 pmid: 20008700

21 Das KM, Lee EY, Singh R, etal. Follow-up chest radiographic findings in patients with MERS-CoV after recovery. Indian I Radiol Imaging 2017;27:342-9. doi: 10.4103/ijri.JIRI_469_16 pmid: 29089687

22 Moldofsky H, Patcai J. Chronic widespread musculoskeletal pain, fatigue, depression and disordered sleep in chronic post-SARS syndrome; a case-controlled study. BMC Neuro/2011;11:37 doi: 10.1186/1471-2377-11-37 pmid: 21435231

23 Zhang T, Sun LX, Feng RE. [Comparison of clinical and pathological features between severe acute respiratory syndrome and coronavirus disease 2019]. Zhonghua lie He He Hu Xi Za Zhi 2020;43:496-502.pmid: 32241072

24 Dasgupta A, Kalhan A, Kalra S. Long term complications and rehabilitation of COVID-19 patients. J Pak Med Assoc 2020;70:S131-5. doi: 10.5455/JPMA.32 pmid: 32515393

25 Galván Casas C, Català A, Carretero Hernández G, etal. Classification of the cutaneous manifestations of COVID-19: a rapid prospective nationwide consensus study in Spain with 375 cases. Br J Dermatol 2020;183:71-7. doi: 10.1111/bjd.19163 pmid: 32348545

26 British Thoracic Society. British Thoracic Society guidance on respiratory follow up of patients with a clinico-radiological diagnosis of COVID-19 pneumonia. 2020. https://www.brit-thoracic.org.uk/document-library/quality-improvement/covid-19/resp-follow-up-guidance-post-covidpneumonia/.

27 Klok FA, Boon GJAM, Barco S, etal. The Post-COVID-19 Functional Status scale: a tool to measure functional status over time after COVID-19. Eur Respir /2020;56: doi: 10.1183/13993003.01494-2020 pmid: 32398306

28 Homerton University Hospital. Post COVID-19 patient information pack. 2020 https://www.hackneycitizen.co.uk/wp-content/uploads/Post-COVID-19-information-pack-5.pdf.

29 Tobin MJ, Laghi F, Jubran A. Why COVID-19 silent hypoxemia is baffling to physicians. AmJ Respir Crit Care Med 2020; doi: 10.1164/rccm.202006-2157CP pmid: 32539537

30 NHS England and NHS Improvement. Pulse oximetry to detect early deterioration of patients with COVID-19 in primary and community care settings. 2020. https://www.england.nhs.uk/coronavirus/publication/pulse-oximetry-to-detect-early-deterioration-of-patients-with-covid-19-inprimary-and-community-care-settings/.

31 NHS England and NHS Improvement. Thousands of patients to benefit from NHS At Home roll-out. 2020. https://www.england.nhs.uk/2020/06/thousands-of-patients-to-benefit-from-nhs-athome-roll-out/.

32 Knight M, Evans D, Vancheeswaran V, et al. A virtual hospital model can help tackle the covid-19 pandemic. Health Service Journal2020. https://www.hsj.co.uk/technology-and-innovation/a-virtual-hospital-model-can-help-tackle-the-covid-19-pandemic/7027340.article.

33 Greenhalgh T, Javid B, Knight M, et al. What is the efficacy and safety of rapid exercise tests for exertional desaturation in covid-19? Oxford COVID-19 Evidence Service, 2020.

https://www.cebm.net/covid-19/what-is-the-efficacy-and-safety-of-rapid-exercise-tests-for-exertional-desaturation-in-covid-19/.

34 NHS England and NHS Improvement. Remote monitoring COVID-19 diary. 2020. https://www.england.nhs.uk/coronavirus/wp-content/uploads/sites/52/2020/06/C0445-remotemonitoring-in-primary-care-annex-2-diary.pdf. 
35 Tarassenko L, Greenhalgh T. Should smartphone apps be used as oximeters? Oxford COVID-19 Evidence Service, 2020. https://www.cebm.net/covid-19/question-should-smartphone-apps-beused-as-oximeters-answer-no//.

36 O'Driscoll BR, Howard LS, Earis J, Mak VBritish Thoracic Society Emergency Oxygen Guideline GroupBTS Emergency Oxygen Guideline Development Group. BTS guideline for oxygen use in adults in healthcare and emergency settings. Thorax 2017;72(Suppl 1):ii1-90. doi: 10.1136/thoraxjnl-2016-209729 pmid: 28507176

37 Collins J-A, Rudenski A, Gibson J, Howard L, O’Driscoll R. Relating oxygen partial pressure saturation and content: the haemoglobin-oxygen dissociation curve. Breathe (Sheff) 2015;11:194-201. doi: 10.1183/20734735.001415 pmid: 2663235

38 Connolly B, O’Neill B, Salisbury L, Blackwood BEnhanced Recovery After Critical Illness Programme Group. Physical rehabilitation interventions for adult patients during critical illness: an overview of systematic reviews. Thorax 2016;71:881-90. doi: 10.1136/thoraxjnl-2015-208273 pmid: 27220357

39 George PM, Wells AU, Jenkins RG. Pulmonary fibrosis and COVID-19: the potential role for antifibrotic therapy. Lancet Respir Med 2020;. doi: 10.1016/S2213-2600(20)30225-3 pmid: 32422178

40 Shi H, Han X, Jiang N, etal. Radiological findings from 81 patients with COVID-19 pneumonia in Wuhan, China: a descriptive study. Lancet Infect Dis 2020;20:425-34. doi: 10.1016/S1473-3099(20)30086-4 pmid: 32105637

41 Pan F, Ye T, Sun P, etal. Time course of lung changes on chest CT during recovery from 2019 novel coronavirus (COVID-19) pneumonia. Radiology 2020; doi: 10.1148/radiol.2020200370.

42 Hull JH, Lloyd JK, Cooper BG. Lung function testing in the COVID-19 endemic. Lancet Respir Med 2020;8:666-7. doi: 10.1016/S2213-2600(20)30246-0 pmid: 32479795

43 Barker-Davies RM, O'Sullivan O, Senaratne KPP, etal. The Stanford Hall consensus statement for post-COVID-19 rehabilitation. Br J Sports Med 2020. doi: 10.1136/bjsports-2020-102596 pmid: 32475821

44 Cillóniz C, Rodríguez-Hurtado D, Torres A. Characteristics and management of community-acquired pneumonia in the era of global aging. Med Sci (Basel) 2018;6:35. doi: 10.3390/medsci6020035 pmid: 29710871

45 Royal College of Occupational Therapists. How to conserve your energy: Practical advice for people during and after having COVID-19. 2020. https://www.rcot.co.uk/conserving-energy,

46 Elliott N, Martin R, Heron N, Elliott J, Grimstead D, Biswas A. Infographic. Graduated return to play guidance following COVID-19 infection. Br J Sports Med 2020; doi: 10.1136/bjsports-2020-102637 pmid: 32571796

47 Larun L, Brurberg KG, Odgaard-Jensen J, Price JR. Exercise therapy for chronic fatigue syndrome. Cochrane Database Syst Rev 2017;4:.pmid: 28444695

48 National Institute for Health and Care Excellence. Statement about graded exercise therapy in the context of COVID-19. In: Myalgic encephalomyelitis (or encephalopathy)/chronic fatigue syndrome: diagnosis and management (in development GID-NG10091). 2020. https://www.nice.org.uk/guidance/gid-ng10091/documents/statement.

49 Shi S, Qin M, Shen B, etal. Association of cardiac injury with mortality in hospitalized patients with COVID-19 in Wuhan, China. JAMA Cardiol 2020;5:802-10. doi: 10.1001/jamacardio.2020.0950 pmid: 32211816

50 European Society of Cardiology. ESC guidance for the diagnosis and management of CV disease during the COVID-19 pandemic. 2020. https://www.escardio.org/Education/COVID-19-and-Cardiology/ESC-COVID-19-Guidance.

51 Yancy CW, Fonarow GC. Coronavirus disease 2019 (COVID-19) and the heart-Is heart failure the next chapter?JAMA Cardio/ 2020; doi: 10.1001/jamacardio.2020.3575. pmid: 32730614

52 Puntmann VO, Carerj ML, Wieters I, etal. Outcomes of cardiovascular magnetic resonance imaging in patients recently recovered from coronavirus disease 2019 (COVID-19). JAMA Cardiol 2020; doi: 10.1001/jamacardio.2020.3557. pmid: 32730619

53 Kochi AN, Tagliari AP, Forleo GB, Fassini GM, Tondo C. Cardiac and arrhythmic complications in patients with COVID-19. J Cardiovasc Electrophysiol 2020;31:1003-8. doi: 10.1111/jce.14479 pmid: 32270559

54 Madjid M, Safavi-Naeini P, Solomon SD, Vardeny O. Potential effects of coronaviruses on the cardiovascular system: a review. JAMA Cardiol 2020;5:831-40. doi: 10.1001/jamacardio.2020.1286 pmid: 32219363

55 Cui S, Chen S, Li X, Liu S, Wang F. Prevalence of venous thromboembolism in patients with severe novel coronavirus pneumonia. J Thromb Haemost 2020;18:1421-4. doi: 10.1111/jth.14830doi: 10.1111/jth.14830 pmid: 32271988

56 Klok FA, Kruip MJHA, van der Meer NJM, etal. Incidence of thrombotic complications in critically ill ICU patients with COVID-19. Thromb Res 2020;191:145-7. doi: 10.1016/j.thromres.2020.04.013 pmid: 32291094

57 British Thoracic Society. BTS guidance on venous thromboembolic disease in patients with COVID-19 (updated 4th May 2020). 2020. https://www.google.co.uk/url?sa=t\&rct=i\&q=\&es$r c=s \&$ source=web\&cd=\&ved=2ahUKEwi2uO_42qnqAhW9QEEAHcDpCFKQFjAAegQIBBAB\&url=https\%3A\%2F\%2Fwww.brit-thoracic.org.uk\%2Fdocument-library\%2Fquality-improvement\%2Fcovid-19\%2Fbts-guidance-on-venous-thromboembolic-disease-in-patients-with-covid19\%2F\&usg=AOVVaw1wijal_6ylc_iYAM2V6TFV.

58 National Institute for Health and Care Excellence. Venous thromboembolic diseases: diagnosis, management and thrombophilia testing (clinical guideline CG144). 2012. https://www.nice.org.uk/guidance/cg144.

59 National Institute for Health and Care Excellence. Chronic heart failure in adults: diagnosis and management (NICE guideline NG106). 2018. https://www.nice.org.uk/guidance/ng106.
60 Pelliccia A, Solberg EF Papadakis M, etal. Recommendations for participation in competitive and leisure time sport in athletes with cardiomyopathies, myocarditis, and pericarditis: position statement of the Sport Cardiology Section of the European Association of Preventive Cardiology (EAPC). Eur Heart J 2019;40:19-33. doi: 10.1093/eurheartj/ehy730 pmid: 30561613

61 Varatharaj A, Thomas N, Ellul MA, etalCoroNerve Study Group. Neurological and neuropsychiatric complications of COVID-19 in 153 patients: a UK-wide surveillance study. Lancet Psychiatry2020; doi: 10.1016/S2215-0366(20)30287-X pmid: 32593341

62 Wang L, He W, Yu X, etal. Coronavirus disease 2019 in elderly patients: Characteristics and prognostic factors based on 4-week follow-up. J Infect 2020;80:639-45. doi: 10.1016/j.jinf.2020.03.019 pmid: 32240670

63 Kemp HI, Corner E, Colvin LA. Chronic pain after COVID-19: implications for rehabilitation. Br J Anaesth 2020;. doi: 10.1016/j.bja.2020.05.021 pmid: 32560913

64 Hoffman GJ, Webster NJ, Bynum JPW. A framework for aging-friendly services and supports in the age of COVID-19. J Aging Soc Policy 2020;32:450-9. doi: 10.1080/08959420.2020.1771239 pmid: 32441572

65 Duan L, Zhu G. Psychological interventions for people affected by the COVID-19 epidemic. Lancet Psychiatry 2020;7:300-2. doi: 10.1016/S2215-0366(20)30073-0 pmid: 32085840

66 Rajkumar RP. COVID-19 and mental health: A review of the existing literature. Asian J Psychiatr 2020;52:. doi: 10.1016/j.ajp.2020.102066 pmid: 32302935

67 World Health Organization. Mental health and psychosocial considerations during the COVID-19 outbreak. 2020. https://www.who.int/docs/default-source/coronaviruse/mental-health-considerations.

68 Rose N, Manning N, Bentall R, etal. The social underpinnings of mental distress in the time of COVID-19 - time for urgent action [preprint]. Wellcome Open Res 2020. https://wellcomeopenresearch.org/articles/5-166/V1.

69 Watt G, Blane D. General practice in the time of COVID-19 (Deep End Report 36). University of Glasgow, 2020. https://www.gla.ac.uk/media/Media_728030_smxx.pdf.

70 Public Health England. Disparities in the risk and outcomes of COVID-19. 2020. https://assets.publishing.service.gov.uk/government/uploads/system/uploads/attachment_data/file/890258/disparities_review.pdf.

71 Finch D, Eastaugh A. How are changes to employment and finances impacting mental health during lockdown? Health Foundation, 2020.

72 NHS England. Your COVID recovery. 2020. www.yourcovidrecovery.nhs.uk.

73 ClinicalTrials.gov. Long-term impact of infection with novel coronavirus (COVID-19) (LIINC). 2020 https://clinicaltrials.gov/ct2/show/record/NCT04362150.

74 ISRCTN Registry. ISRCTN10980107: Long-term follow up of adults hospitalised with COVID-19 2020. http://www.isrctn.com/ISRCTN10980107.

75 Charon R. Narrative medicine: Honoring the stories of illness. Oxford University Press, 2008.

76 NHS England. After-care needs of inpatients recovering from COVID-19 (CO388). 2020. https://www.england.nhs.uk/coronavirus/publication/after-care-needs-of-inpatients-recovering from-covid-19/.

77 Balbi B, Berney S, Brooks D. Report of an ad-hoc international task force to develop an expert-based opinion on early and short-term rehabilitative interventions (after the acute hospita setting) in COVID-19 survivors (version April 3, 2020). European Respiratory Society, 2020. https://ers.app.box.com/s/npzkvigtl4w3pb0vbsth4y0fxe7ae9z9.

78 Grabowski DC, Joynt Maddox KE. Postacute care preparedness for COVID-19: thinking ahead. JAMA 2020;323:2007-8. doi: 10.1001/jama.2020.4686 pmid: 32211831

79 Zhao H-M, Xie Y-X, Wang CChinese Association of Rehabilitation Medicine; Respiratory Rehabilitation Committee of Chinese Association of Rehabilitation Medicine; Cardiopulmonary Rehabilitation Group of Chinese Society of Physical Medicine and Rehabilitation. Recommendations for respiratory rehabilitation in adults with coronavirus disease 2019. Chin Med J (Engl) 2020;133:1595-602. doi: 10.1097/CM9.0000000000000848 pmid: 32251002

80 Pan-American Health Organisation, World Health Organisation. Rehabilitation considerations during the COVID-19 outbreak. 2020. https://iris.paho.org/bitstream/handle/10665.2/52035/NMHMHCOVID19200010_eng.pdf?sequence=6\&isAllowed=y.

81 de Sire A, Andrenelli E, Negrini F, Negrini S, Ceravolo MG. Systematic rapid living review on rehabilitation needs due to COVID-19: update as of April 30th, 2020. Eur J Phys Rehabil Med 2020;56:354-60. doi: 10.23736/S1973-9087.20.06378-9 pmid: 32408729

82 Mukaino M, Tatemoto T, Kumazawa N, etal. Staying active in isolation: telerehabilitation for individuals with the severe acute respiratory syndrome coronavirus 2 infection. Am J Phys Med Rehabil 2020;99:478-9.pmid: 32282339

This article is made freely available for use in accordance with BMJ's website terms and conditions for the duration of the covid-19 pandemic or until otherwise determined by BMJ. You may use, download and print the article for any lawful, non-commercial purpose (including text and data mining) provided that all copyright notices and trade marks are retained. 